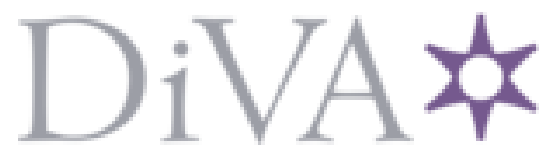

http://www.diva-portal.org

\title{
Postprint
}

This is the accepted version of a paper published in Proceedings of the Combustion Institute. This paper has been peer-reviewed but does not include the final publisher proof-corrections or journal pagination.

Citation for the original published paper (version of record):

Sepman, A., Ögren, Y., Qu, Z., Wiinikka, H., Schmidt, F M. (2017)

Real-time in situ multi-parameter TDLAS sensing in the reactor core of an entrained-flow biomass gasifier.

Proceedings of the Combustion Institute, 36(3): 4541-4548

https://doi.org/10.1016/j.proci.2016.07.011

Access to the published version may require subscription.

N.B. When citing this work, cite the original published paper.

Permanent link to this version:

http://urn.kb.se/resolve?urn=urn:nbn:se:umu:diva-124706 


\section{Real-time in situ multi-parameter TDLAS sensing in the reactor core of}

\section{an entrained-flow biomass gasifier}

Alexey Sepman ${ }^{1}$, Yngve Ögren ${ }^{1}$, Zhechao Qu ${ }^{2}$, Henrik Wiinikka ${ }^{1}$, Florian M. Schmidt ${ }^{2 *}$

${ }^{1}$ SP Energy Technology Center, Box 726, SE-94128, Piteå, Sweden

${ }^{2}$ Thermochemical Energy Conversion Laboratory, Department of Applied Physics and Electronics, Umeå University, SE-90187 Umeå, Sweden

*Thermochemical Energy Conversion Laboratory, Department of Applied Physics and Electronics, Umeå University, KBC-building, Linnaeus väg 6, , SE-90187 Umeå, Sweden, Phone +46 (0)90 7867611, E-Mail: florian.schmidt@umu.se

Colloquium: Diagnostics

Total length of paper (Method 1): 6191 words

Main text: 3796

Equations: 0

Nomenclature: 0

References: 472

Tables: 152

Figure 1: 383

Figure 2: 812

Figure 3: 301

Figure 4: 275

Figures and captions: 1771

Supplemental material is available.

The costs of the color reproduction of Figure 2 will be paid by SP Energy Technology Center. 


\section{Abstract}

Tunable diode laser absorption spectroscopy (TDLAS) was used to measure several important process parameters at two different locations inside the reactor of an atmospheric, air-blown $0.1 \mathrm{MW}_{\text {th }}$ biomass gasifier. Direct TDLAS at $2298 \mathrm{~nm}$ was employed for carbon monoxide $(\mathrm{CO})$ and water vapor $\left(\mathrm{H}_{2} \mathrm{O}\right)$, calibration-free scanned wavelength modulation spectroscopy at $1398 \mathrm{~nm}$ for $\mathrm{H}_{2} \mathrm{O}$ and gas temperature, and direct TDLAS at $770 \mathrm{~nm}$ for gaseous elemental potassium, $\mathrm{K}(\mathrm{g})$, under optically thick conditions. These constitute the first in situ measurements of $\mathrm{K}(\mathrm{g})$ and temperature in a reactor core and in biomass gasification, respectively. In addition, soot volume fractions were determined at all TDLAS wavelengths, and employing fixed-wavelength laser extinction at $639 \mathrm{~nm}$. Issues concerning the determination of the actual optical path length, as well as temperature and species non-uniformities along the line-of-sight are addressed. During a 2-day measurement campaign, peat and stem wood powder were first combusted at an air equivalence ratio (lambda) of 1.2 and then gasified at lambdas of $0.7,0.6,0.5,0.4$ and 0.35 . Compared to uncorrected thermocouple measurements in the gas stream, actual average temperatures in the reactor core were significantly higher. The $\mathrm{CO}$ concentrations at the lower optical access port were comparable to those obtained by gas chromatography at the exhaust. In gasification mode, similar $\mathrm{H}_{2} \mathrm{O}$ values were obtained by the two different TDLAS instruments. The measured $\mathrm{K}(\mathrm{g})$ concentrations were compared to equilibrium calculations. Overall, the reaction time was found to be faster for peat than for stem wood. All sensors showed good performance even in the presence of high soot concentrations, and real-time detection was useful in resolving fast, transient behaviors, such as changes in stoichiometry. Practical implications of in-situ TDLAS monitoring on the understanding and control of gasification processes are discussed.

Keywords: Tunable diode laser absorption spectroscopy, biomass gasification, gas temperature, potassium, carbon monoxide. 


\section{Introduction}

Development of robust and accurate monitoring devices for control of practical energy systems is important [1]. At present, tunable diode laser absorption spectroscopy (TDLAS) is one of the most successful and rapidly developing technologies applied in practical systems [2]. TDLAS sensors enable fast and calibration-free in situ measurements of both gas temperature (T) and species concentrations, which has already been demonstrated in full sized coal fired power plants [3] and waste incinerators [4]. Another system, where TDLAS can make a significant contribution, is biomass-fired entrained-flow gasification (EFG) aimed to produce gas for heat and power generation, chemicals and motor fuels. Investigations in pilot-scale EFGs for wood powder [5] and black liquor [6] have shown a large potential for efficiency increase, which is needed for commercialization.

During EFG of biomass, small fuel particles $(<1 \mathrm{~mm})$ react with a controlled (under-stoichiometric) amount of air, oxygen and/or steam at high $\mathrm{T}\left(>1000^{\circ} \mathrm{C}\right)$, producing an energy-rich gas mainly consisting of $\mathrm{H}_{2}, \mathrm{CO}, \mathrm{CO}_{2}, \mathrm{H}_{2} \mathrm{O}$, and $\mathrm{CH}_{4}[7,8]$. High amounts of dust are present that consists of unconverted char, large fly ash particles [9] and submicron particles including both soot and volatile ash forming elements [10]. Often, gaseous potassium $(\mathrm{K})$ compounds, mainly atomic $\mathrm{K}$, potassium chloride $(\mathrm{KCl})$ and potassium hydroxide $(\mathrm{KOH})$, and fly ash particles containing $\mathrm{K}$ form a corrosive melt on the walls of the reactor that can break down the ceramic insulation [9]. The harsh environment inside the reactor is problematic with respect to process monitoring using intrusive methods.

Traditionally, the reactor temperature is measured by thermocouples (TCs) installed in the refractory lining or the gas stream, and the gas composition is analyzed with gas chromatography (GC) in the syngas pipe downstream of the reactor [8]. Since the TC reading is heavily biased by heat transfer from the gas to the refractory lining, and by accumulating deposits, accurate gas temperature assessment is often not possible without complex correction methods. Also, the gas composition may change when the gas cools down in the gasifier quench prior to GC analysis. Established monitoring systems often are too slow to adequately respond to sudden changes in the reactor process, thereby posing a risk to plant security. In 
addition, experimental data from inside the reactor core is needed for a better understanding of the gasification process itself. Thus, there is a large incentive to develop fast in situ sensor systems based on TDLAS.

Some encouraging results from pressurized coal fired gasifiers have been presented by the Hanson group at Stanford University [11-13]. Most of the data, i.e. concentrations of $\mathrm{CO}, \mathrm{CO}_{2}, \mathrm{CH}_{4}$, and $\mathrm{H}_{2} \mathrm{O}$, were, however, collected downstream of the hot reactor in the relatively cold flue gases, only temperature was measured inside the hot reactor core $\left(\mathrm{T} \sim 1400{ }^{\circ} \mathrm{C}\right)[11]$. Other groups have used TDLAS to measure low concentrations of $\mathrm{K}(\mathrm{g})$ in the flue gas of an industrial coal combustion plant [14] and to detect $\mathrm{HCl}$, $\mathrm{H}_{2} \mathrm{O}$ and $\mathrm{CO}$ in the reactor core of a biomass gasifier $[15,16]$.

In this paper, we report on progress regarding the development and application of TDLAS sensors for real-time in situ measurement of gas temperature, species concentration $\left(\mathrm{CO}, \mathrm{H}_{2} \mathrm{O}\right.$, elementary $\left.\mathrm{K}\right)$ and soot particle volume fraction inside the reactor core $\left(\mathrm{T}>1100^{\circ} \mathrm{C}\right)$ of a biomass-fired $\mathrm{EFG}$. With an eye on the potential of the TDLAS for process control and understanding, we investigated the sensitivity of the parameters to variations in gasification conditions (fuel, stoichiometry) at two different locations in the reactor. The obtained data are compared to thermocouple and GC readings, as well as to chemical equilibrium calculations for potassium.

\section{Experimental setup and procedure}

\subsection{Reactor facility}

The experiments were conducted in an $4 \mathrm{~m}$ long, air-blown, atmospheric EFG (Fig. 1) operated at 0.1 $\mathrm{MW}_{\text {th }}[17]$. The gasifier has the shape of a standing cylinder with flat top and conical bottom. The reactor core has an inner diameter of $50 \mathrm{~cm}$ and is enclosed by $20 \mathrm{~cm}$ of refractory lining in the outer steel shell. The fuel was pneumatically feed from a feed hopper and entered the EFG centrally from the top through an axial burner forming a jet type of flame. The average fuel consumption rate during operation was $\sim 20.2$ $\mathrm{kg} /$ hour. Before initial introduction of the biomass, the EFG was preheated by oil combustion. After the 
reactor, the gaseous products were burned in a boiler. Two powder fuels were used (Table S1), one consisting of peat (Peat, $5.7 \%$ ash, $0.058 \% \mathrm{~K}$ ), the other of stem wood from pine and spruce (Wood, $0.3 \%$ ash, $0.034 \% \mathrm{~K})$. Compared to Wood, Peat has a lower volatile content and a finer powder size distribution. Downstream, a part of the reactor gas was withdrawn and its composition analyzed using GC with a thermal conductivity detector (GC-TCD). The temperature in both refractory lining and the center of the gas stream was measured close to the optical access ports with K-type TCs installed in $8 \mathrm{~mm} \mathrm{Al}_{2} \mathrm{O}_{3}$ tubes for protection.
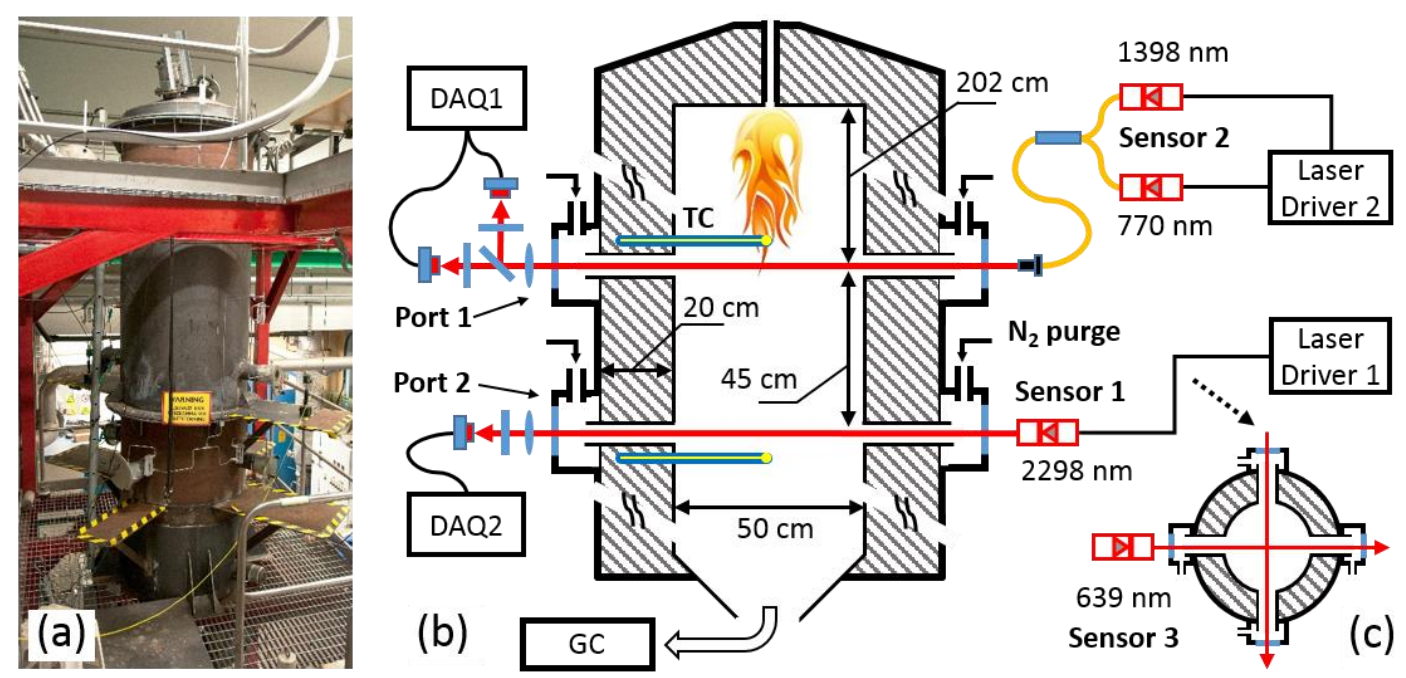

Fig. 1. (a) Photograph of the biomass gasifier at SP ETC Piteå, Sweden, (b) schematic of the gasifier including the optical access port configuration and the experimental TDLAS sensor setup, DAQ-data acquisition system, (c) topview of Port 2.

Helium was seeded $(5 \mathrm{~L} / \mathrm{min})$ to the burner to enable absolute quantification of the total amount of gas produced (Table S2) and the species measured by GC-TCD. Given the known initial carbon content in the fuel and the produced amounts of $\mathrm{CO}, \mathrm{CO}_{2}, \mathrm{CH}_{4}, \mathrm{C}_{2} \mathrm{H}_{2}$ and $\mathrm{C}_{2} \mathrm{H}_{4}$, the carbon converted to gas phase was calculated. Assuming that all unconverted carbon turns into soot, and using a soot particle density of $1.84 \mathrm{~g} / \mathrm{cm}^{3}$ [18], soot volume fractions could be estimated from the GC data. Below, the soot volume fraction estimated in this way will be referred to as unburned carbon fraction (UCF). 


\subsection{TDLAS sensor setup}

A direct TDLAS system (Sensor 1) at $2298 \mathrm{~nm}$ was employed for calibration-free measurements of CO and $\mathrm{H}_{2} \mathrm{O}$ [19]. The laser wavelength was tuned over a wavenumber range of up to $4 \mathrm{~cm}^{-1}$ in $1.1 \mathrm{~ms}$ or 11 ms by modulating the laser current with a triangular wave, and spectra were saved every $0.1 \mathrm{~s}$. The CO and $\mathrm{H}_{2} \mathrm{O}$ concentrations reported below represent the average of a measurement series (1000 scans), where each spectrum was evaluated separately. The single scan detection limits were $1000 \mathrm{ppmv}$ for CO and 3000 ppmv for $\mathrm{H}_{2} \mathrm{O}$, and the estimated uncertainties in the reactor core were $15 \%$ and $20 \%$ for $\mathrm{CO}$ and $\mathrm{H}_{2} \mathrm{O}$, respectively. The initial part of the voltage ramp was below the laser threshold, which allowed determination of the background radiation at the time of the scan.

A second TDLAS system (Sensor 2), based on distributed feedback lasers, was used to simultaneously measure $\mathrm{H}_{2} \mathrm{O}$ and $\mathrm{T}$ at $1398 \mathrm{~nm}$ with calibration-free scanned wavelength modulation spectroscopy (CFWMS) [20, 21], and $\mathrm{K}(\mathrm{g})$ at $769.9 \mathrm{~nm}$ with direct TDLAS [22]. The laser scan frequencies were $80 \mathrm{~Hz}$ and $200 \mathrm{~Hz}$ and the scan ranges $2.3 \mathrm{~cm}^{-1}$ and $4 \mathrm{~cm}^{-1}$, respectively. A CF-WMS modulation frequency of $8 \mathrm{kHz}$ was employed. Each recorded spectrum was an average of ten scans. Temperature was assessed by two-line thermometry on $\mathrm{H}_{2} \mathrm{O}$ transitions with linear T dependence in the range 1200-1800 K [20]. The CF-WMS fitting procedure allows simultaneous determination of wavelength-dependent modulation amplitude, $\mathrm{H}_{2} \mathrm{O}$ concentration and temperature from a single curve fit to a group of $1 f$ - or $d c$-normalized $2 f$-WMS lineshapes. The detection limit for $\mathrm{H}_{2} \mathrm{O}$ was 1000 ppmv. Measurement uncertainties of $1 \%$ for $\mathrm{H}_{2} \mathrm{O}$ and $50 \mathrm{~K}$ for temperature have previously been determined under homogenous conditions in a flat flame with known path-length [21]. The $\mathrm{K}(\mathrm{g})$ setup had a dynamic range of $40 \mathrm{pptv} \cdot \mathrm{cm}$ to $40 \mathrm{ppmv} \cdot \mathrm{cm}$ and was adapted for measurements under optical thick and partially opaque conditions, which, given the large product of linestrength and path length, can easily occur for typical $\mathrm{K}(\mathrm{g})$ concentrations in gasification.

Sensors 1 and 2 were also used to detect soot via transmittance variations in the baseline. For the selected port locations and laser scanning rates, the variation due to soot manifested itself as broadband 
(wavelength-independent) reduction of the transmitted signal, while for fuel particles the spectra were distorted. In addition, soot was determined by laser extinction (LE) at $639 \mathrm{~nm}$ (Sensor 3). From the transmittance, soot volume fractions were calculated following the approach in [23], with the refractive index supplied by [18] reported for wavelengths $0.4-40 \mu \mathrm{m}$. The integration of the three sensors in the reactor setup is schematically shown in Fig. 1b. For Sensor 2 (laser beam diameter $1 \mathrm{~mm}$ ), single scans were practically undisturbed ( $<1 \%$ disregarded spectra) during the whole campaign. The same was true for $1.1 \mathrm{~ms}$ scans recorded with Sensor 1 ( $5 \mathrm{~mm}$ beam diameter). In contrast, the $11 \mathrm{~ms}$ scans were more often distorted (up to $50 \%$ disregarded spectra), probably due to unburned fuel particles crossing the laser beam. For all LE measurements a particle size much smaller than the laser wavelength was assumed.

The optical access port windows, mounted on extensions (diameter $2 \mathrm{~cm}$ ) to the gasifier wall, were flushed with $\mathrm{N}_{2}$ to prevent window fouling and the intrusion of reactor gases into the extensions. The influence of the $\mathrm{N}_{2}$ flow on the measured species was investigated for flow rates from 0.2 to $20 \mathrm{~L} / \mathrm{m}$. An intrusion of the reactor gases into the extensions was not noticed, and the concentrations decreased slightly with increasing $\mathrm{N}_{2}$ flow rate. A flow rate of $2 \mathrm{~L} / \mathrm{m}$ was chosen for the campaign, and in the following, the optical path length is considered equal to the inner diameter of the gasifier.

In order to minimize the effects of potential temperature and gas non-uniformities, we selected transition with a modest or linear T dependence. In the range 1200-1800 K, the two $\mathrm{H}_{2} \mathrm{O}$ transitions used by Sensor 2 allow determination of the density-weighted path-averaged temperature [24], which was then used to convert $\mathrm{H}_{2} \mathrm{O}$ column density to concentration. The linestrength/T ratio of the $\mathrm{CO} \mathrm{R} 34$ and $\mathrm{R} 35$ transitions used by Sensor 1 changes only within $10 \%$ between 1000 and $1900 \mathrm{~K}$, which enables calculation of the $\mathrm{CO}$ concentration directly from the integrated absorbance. The linestrength of the $\mathrm{H}_{2} \mathrm{O}$ transition at $2299.2 \mathrm{~nm}$ changes within $15 \%$ between 1100 and $2000 \mathrm{~K}$, therefore, the column density obtained from the spectra (using T from Sensor 2), could be converted to $\mathrm{H}_{2} \mathrm{O}$ concentration. Similarly, the $\mathrm{K}(\mathrm{g})$ column density was determined employing the average $\mathrm{H}_{2} \mathrm{O}$ temperature, and then converted to 
$\mathrm{K}(\mathrm{g})$ concentration. The linestrength of the D1 potassium transition changes about $40 \%$ in the interval $1000-1800 \mathrm{~K}$.

\subsection{Experimental procedure}

A 2-day measurement campaign firing Peat (Day 1) and Wood (Day 2) was conducted in the EFG using the described sensor systems. In the morning of Day 1, Sensor 2 was measuring at the upper Port 1, whereas Sensors 1 and 3 were installed at the lower Port 2 (Fig. 1c). In the afternoon of Day 1, Sensors 1 and 2 switched position. On Day 2, Sensor 1 started out at Port 1 and was at Port 2 in the afternoon, whereas it was the opposite for Sensor 2. The different sensors and measurement locations during the campaign are summarized in Table 1 . On both campaign days, in the morning and in the afternoon, the gasifier was first run in the combustion mode at an air equivalence ratio (lambda) of 1.2 , and then in the gasification mode, successively going through lambdas $0.7,0.6,0.5,0.4$ and 0.35 . The main results obtained during the campaign are summarized in Figure 2.

Table 1

Location of the sensors during the 2-day campaign.

\begin{tabular}{llllllll}
\hline Sensor & Technique & Detection & \multicolumn{2}{l}{ Wavelength } & \multicolumn{2}{l}{ Day 1-Peat } & \multicolumn{2}{c}{ Day 2-Wood } \\
\cline { 5 - 7 } & & & am & pm & am & pm \\
\hline 1 & direct TDLAS & $\mathrm{CO}, \mathrm{H}_{2} \mathrm{O}$, soot & 2298 & Port 2a & Port 1 & Port 1 & Port 2a \\
2 & CF-WMS & $\mathrm{T}, \mathrm{H}_{2} \mathrm{O}$, soot & 1398 & Port 1 & Port 2a & Port 2a & Port 1 \\
2 & direct TDLAS & $\mathrm{K}(\mathrm{g})$ & 769.9 & Port 1 & Port 2a & Port 2a & Port 1 \\
3 & LE & soot & 635 & Port 2b & Port 2b & Port 2b & Port 2b \\
\hline
\end{tabular}

\section{Results and discussion}

\subsection{Temperature, carbon monoxide and water vapor}

Figures $2 \mathrm{a}$ and $2 \mathrm{~b}$ present time-resolved TDLAS data of the density-weighted path-averaged $\mathrm{T}$ in the reactor core of the EFG for Peat and Wood, respectively. The figures also displays the corresponding lambda and the temperature recorded by the TCs at the center of the reactor. For both fuels, the 
temperatures were highest (around $1870 \mathrm{~K}$ ) in the combustion mode at Port 1, and about $300 \mathrm{~K}$ lower at Port 2. This suggests that maximum heat release occurs upstream of Port 2 for both fuels at this lambda. In gasification mode, the measured temperature is significantly lower and little affected by changes in equivalence ratio. In Wood gasification, T variations are larger ( 100 K) compared to Peat $(50-75 \mathrm{~K})$, probably caused by larger variations in the feeding of the Wood powder. For both fuels and ports, and all stoichiometries, the TC readings were considerably lower than the temperature measured by TDLAS, the difference being largest in combustion. This is in accordance with the estimated radiative correction factor for TCs, which is about $500 \mathrm{~K}$ under optically thin (combustion) conditions, and decreases with increasing soot concentration in the gasification mode. The radiation correction for the combustion mode was estimated similar to that in [25]. The correction assumed a protective tube with a diameter of $6 \mathrm{~mm}$ and emissivity of 0.41 (aluminum oxide at $1500 \mathrm{~K}$ ), and an estimated flow velocity around the TC of $4 \mathrm{~m} / \mathrm{s}$, resulting in a Nusselt number of 6.72 (external flow around cylinder).

Figures $2 \mathrm{c}$ and $2 \mathrm{~d}$ show $\mathrm{CO}$ and $\mathrm{H}_{2} \mathrm{O}$ TDLAS data as well as dry $\mathrm{CO}$ measured by GC for Peat and Wood, respectively. The Sensor $1 \mathrm{CO}$ and Sensor $2 \mathrm{H}_{2} \mathrm{O}$ concentrations are reported in real time, whereas the Sensor $1 \mathrm{H}_{2} \mathrm{O}$ results are given as average value for each lambda to increase readability. As expected, and in accordance with the GC data, CO increases with decreasing lambda for both fuels and ports. At Port 2, CO is slightly higher than that at Port 1, and Peat produces around $30 \%$ more CO than Wood in gasification. In general, the GC measured higher CO concentrations than TDLAS, for Peat within $20 \%$ at Port 1 and $15 \%$ at Port 2, and for Wood within $40 \%$ at Port 1 and $20 \%$ at Port 2 . This indicates that, during Peat gasification, the $\mathrm{CO}$ concentration was close to equilibrium already at the upper port. 

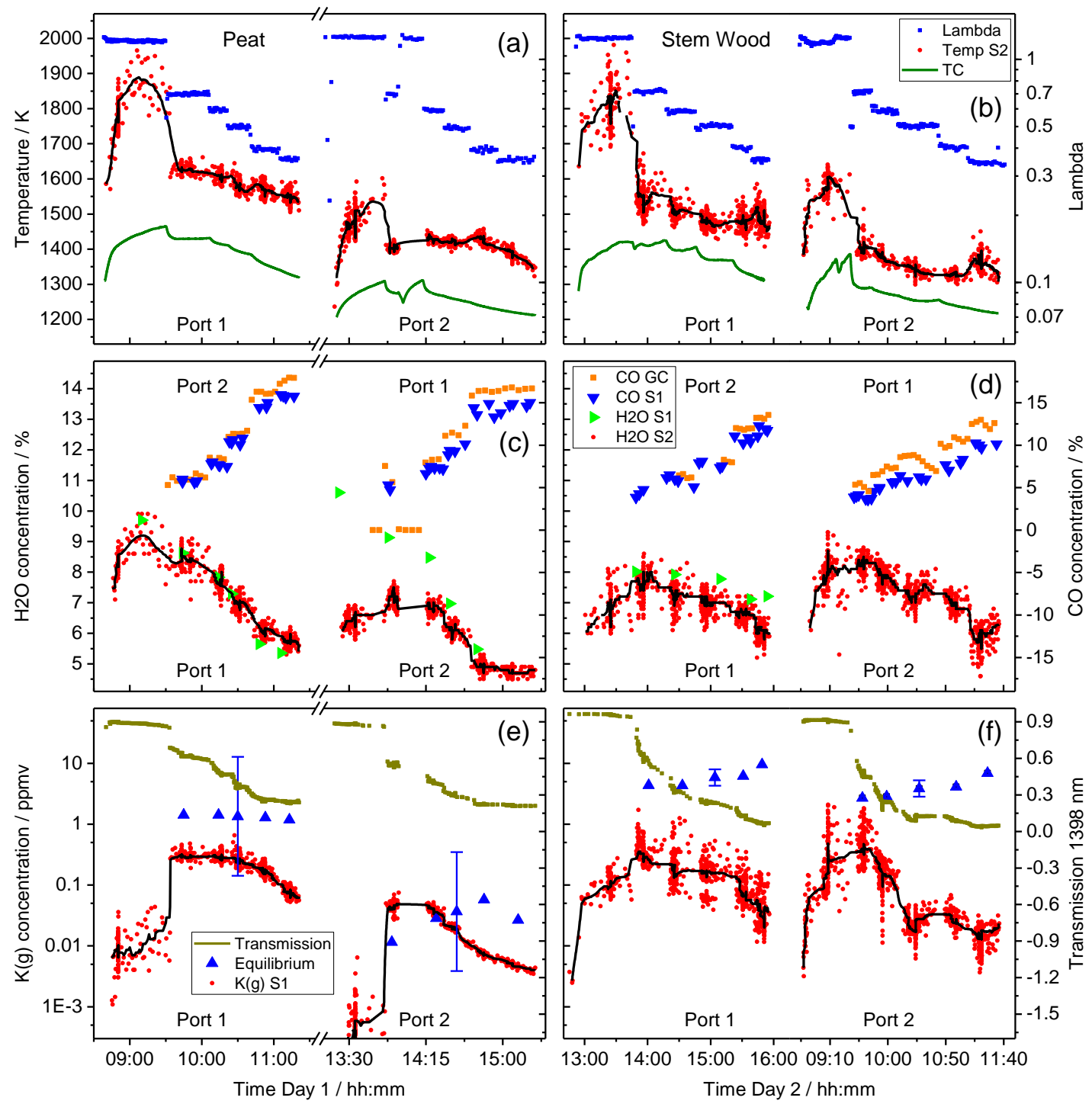

Fig. 2. Results of the TDLAS measurements at Ports 1 and 2 of the EFG reactor firing Peat (Day 1, left column) and Wood (Day 2, right column) at lambdas of 1.2, 0.7, 0.6, 0.5, 0.4 and 0.35. (a and b) lambda, density-weighted path-averaged gas temperature (Sensor 2, S2) and gas stream TC reading, (c and d) CO, $\mathrm{H}_{2} \mathrm{O}$ (Sensor 1, S1), CO (GC) and $\mathrm{H}_{2} \mathrm{O}$ (Sensor 2), (e and f) transmission at $1389 \mathrm{~nm}, \mathrm{~K}(\mathrm{~g}$ ) concentration (Sensor 2) and equilibrium values. At all times during the campaign, Sensors 1 and 2 were installed at different ports. Black lines constitute a SavitzkyGolay smooth of the real-time data (red, circular markers). Representative error bars assuming a $\pm 100 \mathrm{~K}$ uncertainty in temperature were added to the calculated $\mathrm{K}(\mathrm{g})$ equilibrium values.

The $\mathrm{H}_{2} \mathrm{O}$ concentrations decrease gradually with decreasing lambda, and, in general, agree well (within 15-20\%) between the two TDLAS sensors. Similar to what was observed for T, the $\mathrm{H}_{2} \mathrm{O}$ variations 
are larger for Wood than for Peat. However, for Peat at Port 2 at lambdas 1.2, 0.7 and 0.6, Sensor 2 shows a significantly lower concentration than Sensor 1 . Also, for Peat, Sensor 2 measured lower $\mathrm{H}_{2} \mathrm{O}$ at Port 2 than at Port 1 . Given the low average temperature at Port 2, actual gas temperatures near the walls of the gasifier could have been below $1200 \mathrm{~K}$, and thus outside the operating range of Sensor 2. As the linestrengths of the employed $\mathrm{H}_{2} \mathrm{O}$ transition have their maximum around $1000 \mathrm{~K}$ [20], the obtained results may be biased towards the lower temperatures along the line-of-sight in the reactor. The fact that Sensor 2 showed lower $\mathrm{H}_{2} \mathrm{O}$ in combustion than in gasification for Wood at Port 1 is probably connected to gasifier operational problems in the afternoon of Day 2.

\subsection{Atomic potassium}

The measured $\mathrm{K}(\mathrm{g})$ concentrations for Peat and Wood are displayed in Figures 2e and 2f, respectively, together with equilibrium concentrations and the broadband transmittance at $1398 \mathrm{~nm}$. Thermochemical equilibrium calculations for $\mathrm{K}(\mathrm{g})$ were performed with FactSage (GTT Technologies), and considered ashes and externally added air at the density-weighted path-averaged T measured by Sensor 2. Solid, liquid and gas phase compositions were taken into account following the work of Carlsson et al. [9]. As can be seen from Figure 2, the $\mathrm{K}(\mathrm{g})$ concentrations were much lower in combustion than in gasification mode due to the presence of excess oxygen. During gasification, $\mathrm{K}(\mathrm{g})$ decreases significantly with decreasing lambda and temperature for both fuels. For Peat, there is also a considerable decrease between Port 1 and Port 2 (maybe connected to T decrease), but this is not the case for Wood, which is another indication that Wood was not fully converted at Port 2. As for temperature and $\mathrm{H}_{2} \mathrm{O}$, but even more pronounced, the overall variations in $\mathrm{K}(\mathrm{g})$ were smaller for Peat than for Wood, and decreased for Peat at Port 2, which indicates a more homogenous distribution for Peat. In contrast, the large $\mathrm{K}(\mathrm{g})$ fluctuations during Wood conversion suggest that the flame at times extended down to Port 2. Based on the initial K content in the fuel and the total amount of gas produced (Table S2), it was found that only $0.1-1 \%$ of the released $\mathrm{K}$ is present as $\mathrm{K}(\mathrm{g})$ in gasification. 
The discrepancy between the measured and equilibrium $\mathrm{K}(\mathrm{g})$ concentrations can have several reasons. First, chemical reaction may still be ongoing, especially at Port 1, and for Wood, even at Port 2. Second, the fuel and ash elemental analyses (Table S1), which constitute the basis of the equilibrium calculations, have a high uncertainty $(\sim 15 \%)$, especially for Wood (low ash content). Third, since the potassium chemistry strongly depends on temperature and most of the $\mathrm{K}(\mathrm{g})$ will appear in the vicinity of burning particles in the entrained flame at the center of the gasifier, the distribution of $\mathrm{K}(\mathrm{g})$ along the line-of-sight may differ from the distribution of $\mathrm{H}_{2} \mathrm{O}$. As a consequence, the $\mathrm{H}_{2} \mathrm{O}$-derived density-weighted pathaveraged $\mathrm{T}$ may not represent the actual average $\mathrm{T}$ for $\mathrm{K}(\mathrm{g})$, and the actual absorption path length for $\mathrm{K}(\mathrm{g})$ could be smaller than the inner diameter of the EFG. In an attempt to account for the discussed uncertainties in the equilibrium calculations, at least partly, an error bar was added to the $\mathrm{K}(\mathrm{g})$ equilibrium values presented in Fig. 2 based on assumed $\mathrm{T}$ distributions that give a $\pm 100 \mathrm{~K}$ variation in the average $\mathrm{T}$. A good agreement is achieved for Peat. The difference in the $\mathrm{K}(\mathrm{g})$ sensitivity to temperature between Peat and Wood is a results of the different chemical composition of the ash in the fuels. The influence of these factors on $\mathrm{K}(\mathrm{g})$ will be subject of future investigations.

\subsection{Soot and carbon conversion}

Figure 3 presents soot volume fractions calculated from the measured broadband transmittance at three laser wavelengths as a function of lambda for Peat (panel a) and Wood (panel b). The UCF determined from GC-TCD analysis, and the carbon conversion calculated using He tracing are also shown (at Port 2). Each data point represents an average of all measurements conducted at a fixed lambda. Clearly, the soot volume fractions increase with decreasing lambda. This would still hold if the soot volume fractions were corrected for the decrease in produced gas volume (Table S2) with decreasing lambda. The fact that Wood produces more soot than Peat can most likely be explained by the lower volatile content of Peat. The GCderived UCF is significantly larger as it represents the maximum possible soot level in the system. 

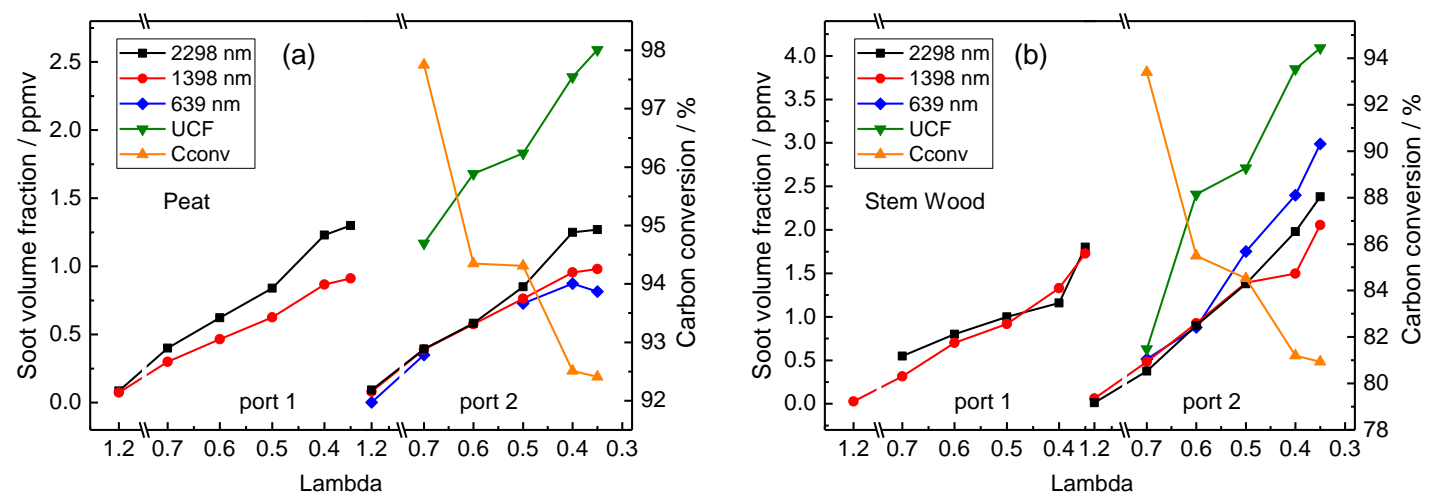

Fig. 3. Soot volume fractions and carbon conversion as a function of stoichiometry for Peat (a) and Wood (b) at both ports, determined with the different sensors. Results from Sensors 1 and 2 are from different times during the campaign.

Between the sensors, the obtained soot concentrations agree reasonably well down to lambda 0.5 , but show an increasing difference at lower lambdas. In the case of Peat, higher wavelengths give higher soot concentrations, whereas the behavior is opposite for Wood. Previous studies on Wood [17] revealed that the soot aerodynamic diameter increases gradually with decreasing lambda and is at least a factor of 2 larger than for Peat. This suggests that, for Wood, the Rayleigh criterion is violated at $639 \mathrm{~nm}$ and that the contribution of scattering to the reduction in transmittance of Sensor 3 can explain the difference to Sensors 1 and 2. In combustion mode (negligible soot), the broadband transmittance reduction was $<10 \%$ for Peat and only a few percent for Wood (in accordance with the ash content, Table S1), which indicates that small fly ash particles contributed only slightly to light extinction.

\subsection{Real-time monitoring of multiple gasification parameters}

Figures $4 \mathrm{a}$ and $4 \mathrm{~b}$ display a few seconds of real-time data at Port 2 during Wood gasification recorded with Sensor 1 (CO, soot and background radiation) and Sensor 2 (temperature, $\mathrm{H}_{2} \mathrm{O}$, $\mathrm{K}$ and soot), respectively. In Fig. 4a, every point represents data from a single scan at $10 \mathrm{~Hz}$, whereas, in Fig 4b, it is the average of 10 scans. A clear correlation can be seen between all three parameters in Fig 4a, as soot is closely related to carbon species, and a part of the background signal apparently originates from soot 
emission. In Fig. 4b, there is a positive correlation between $\mathrm{T}$ and $\mathrm{K}(\mathrm{g})$ and those two correlate negatively with soot. A correlation with $\mathrm{H}_{2} \mathrm{O}$ was not observed. Since a $200 \mathrm{~K}$ increase in $\mathrm{T}$ only leads to a $15 \%$ decrease in $\mathrm{K}$ linestrength (and an according increase in $\mathrm{K}(\mathrm{g})$ concentration), the correlation between $\mathrm{T}$ and $\mathrm{K}(\mathrm{g})$ is mostly related to chemistry. It is likely that the variations in these parameters are related to actual changes in lambda due to fluctuations in the biomass feeding. Similar variations have been observed at other stoichiometries for all fuels and ports.
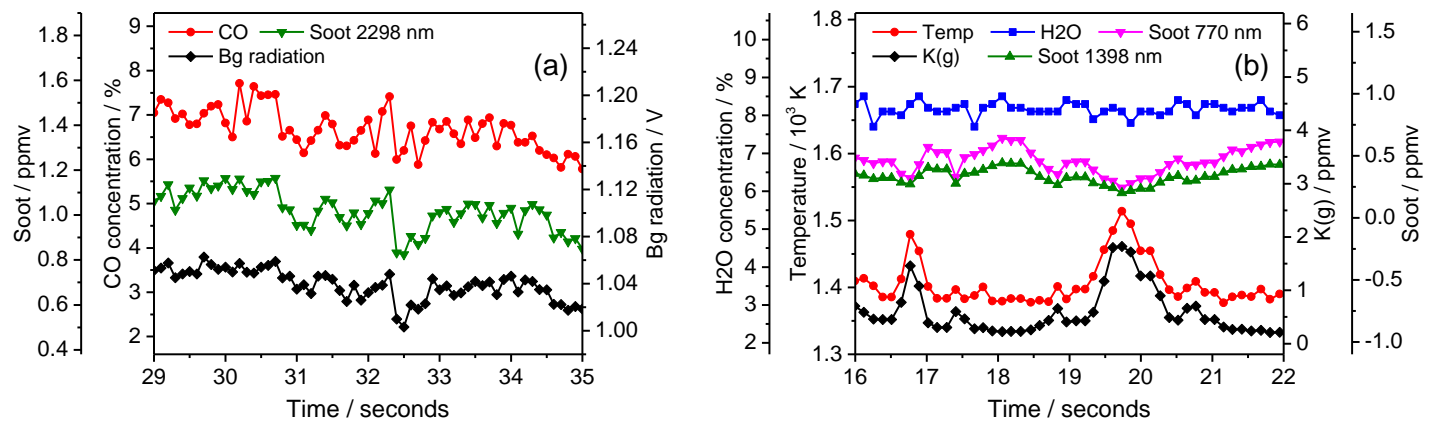

Fig. 4. Several seconds of real-time data from inside the EFG reactor core for Wood at Port 2. (a) CO, soot and background emissions for lambda 0.6 with Sensor 1, (b) gas temperature, $\mathrm{H}_{2} \mathrm{O}, \mathrm{K}(\mathrm{g})$ and soot for lambda 0.7 with Sensor 2.

\subsection{Practical implications for biomass gasification}

From the simultaneous quantification of process parameters, such as $\mathrm{T}, \mathrm{CO}, \mathrm{H}_{2} \mathrm{O}, \mathrm{K}(\mathrm{g})$ and soot, at different locations inside the EFG reactor core, valuable information on the gasification process can be obtained. For example, the measurements indicate that the reaction time is faster for Peat than for Wood, and a comparison between TDLAS and GC CO concentrations provides information on how far the reactor $\mathrm{CO}$ is away from its final value. The advantages of TDLAS compared to TCs have to be clearly emphasized. With TDLAS, the gas temperature can be assessed calibration- and correction-free, fast, and without sensor degradation. Knowledge of reactor soot concentrations is important in commercial EFGs, where soot particles are separated from the gas flow in the quench, and thus difficult to measure. In the future, the monitoring of soot, $\mathrm{T}$ and all major hydrocarbon species $\left(\mathrm{CO}, \mathrm{CO}_{2}\right.$ and $\left.\mathrm{CH}_{4}\right)$ in the reactor core, 
could provide continuous information on the carbon conversion in the system, which will help to operate the gasifier under optimal conditions. The benefit of real-time detection is instant information on process abnormalities, and parameters such as feeding rate and lambda. The potassium concentration inside the reactor can be an important indicator for fine-particle production and degradation of ceramic insulation materials. A robust $\mathrm{K}(\mathrm{g})$ sensor could also help to identify the optimum fuel blend and to control the amount of additives applied to minimize ash-related operational problems.

\section{Conclusions}

We demonstrate simultaneous real-time detection of gas temperature, $\mathrm{CO}, \mathrm{H}_{2} \mathrm{O}, \mathrm{K}(\mathrm{g})$ and soot at two locations in the reactor core of a pilot-scale biomass gasifier during a 2-day campaign. From the obtained data, we deduce the density-weighted, path-averaged temperature (for $\mathrm{H}_{2} \mathrm{O}$ ), as well as species and soot concentrations, and can draw conclusions regarding the progress of gasification. The TDLAS sensors performed well under harsh, high-temperature conditions and in the presence of high soot concentrations. Accurate quantification of $\mathrm{K}(\mathrm{g})$ is currently limited by lack of information on the density-weighted pathaveraged $\mathrm{T}$ for $\mathrm{K}(\mathrm{g})$, and the effective $\mathrm{K}(\mathrm{g})$ path length. However, process information can be obtained from the relative $\mathrm{K}(\mathrm{g})$ changes with fuel, residence time and stoichiometry. Without doubt, TDLAS sensors hold great promise for process characterization, monitoring and control in combustion and gasification applications.

\section{Acknowledgements}

The authors acknowledge financial support from the Swedish Research Council, the Swedish Energy Agency, the Kempe Foundations, the Swedish strategic research program Bio4Energy and the Swedish Center for Gasification.

\section{References}

1. J. Ballester, T. García-Armingol, Prog. Energ. Combust. 36 (4) (2010) 375-411. 
2. R. K. Hanson, P. Combust. Inst. 33 (1) (2011) 1-40.

3. H. Teichert, T. Fernholz, V. Ebert, Appl. Opt. 42 (12) (2003) 2043-2051.

4. V. Ebert, H. Teichert, P. Strauch, T. Kolb, H. Seifert, J. Wolfrum, P. Combust. Inst. 30 (1) (2005) 1611-1618.

5. F. Weiland, H. Wiinikka, H. Hedman, J. Wennebro, E. Pettersson, R. Gebart, Fuel 153 (2015) 510519.

6. H. Wiinikka, A.-C. Johansson, J. Wennebro, P. Carlsson, O. G. Öhrman, Fuel Process. Technol. 139 (2015) 216-225.

7. H. Wiinikka, P. Carlsson, F. Granberg, J. Löfström, M. Marklund, R. Tegman, M. Lindblom, R. Gebart, Fuel 89 (9) (2010) 2583-2591.

8. F. Weiland, H. Hedman, M. Marklund, H. Wiinikka, O. Öhrman, R. Gebart, Energ. Fuel. 27 (2) (2013) 932-941.

9. P. Carlsson, C. Ma, R. Molinder, F. Weiland, H. Wiinikka, M. Öhman, O. Öhrman, Energ. Fuel. 28 (11) (2014) 6941-6952.

10. H. Wiinikka, F. Weiland, E. Pettersson, O. Öhrman, P. Carlsson, J. Stjernberg, Combust. Flame 161 (7) (2014) 1923-1934.

11. K. Sun, R. Sur, X. Chao, J. B. Jeffries, R. K. Hanson, R. J. Pummill, K. J. Whitty, P. Combust. Inst. 34 (2) (2013) 3593-3601.

12. R. Sur, K. Sun, J. B. Jeffries, R. K. Hanson, Appl. Phys. B 115 (1) (2014) 9-24.

13. R. Sur, K. Sun, J. B. Jeffries, J. G. Socha, R. K. Hanson, Fuel 150 (2015) 102-111.

14. E. Schlosser, J. Wolfrum, L. Hildebrandt, H. Seifert, B. Oser, V. Ebert, Appl. Phys. B 75 (2-3) (2002) 237-247.

15. P. Ortwein, W. Woiwode, S. Fleck, M. Eberhard, T. Kolb, S. Wagner, M. Gisi, V. Ebert, Exp. Fluids 49 (4) (2010) 961-968. 
16. P. Ortwein, In-situ-Laserspektroskopie für Vergasungs-und Verbrennungsprozesse: direkte Bestimmung absoluter Gaskonzentrationen und neuer Spektralparameter, $\mathrm{PhD}$ thesis, University of Heidelberg, Heidelberg, Germany, 2011.

17. J. Simonsson, H. Bladh, M. Gullberg, E. Pettersson, A. Sepman, Y. Ögren, H. Wiinikka, P.-E. Bengtsson, Energ. Fuel. 30 (3) (2016) 2174-2186.

18. H. Chang, T. Charalampopoulos, Proc. R. Soc. Lond. A 430 (1880) (1990) 577-591.

19. A. Sepman, Y. Ögren, M. Gullberg, H. Wiinikka, Appl. Phys. B 122 (2) (2016) 1-12.

20. Z. Qu, F. M. Schmidt, Appl. Phys. B 119 (1) (2015) 45-53.

21. Z. Qu, R. Ghorbani, D. Valiev, F. M. Schmidt, Opt. Express 23 (12) (2015) 16492-16499.

22. Z. Qu, E. Steinvall, R. Ghorbani, F. M. Schmidt, Anal. Chem. 88 (7) (2016) 3754-3760.

23. A. Lamprecht, W. Eimer, K. Kohse-Höinghaus, Combust. Flame 118 (1) (1999) 140-150.

24. C. S. Goldenstein, I. A. Schultz, J. B. Jeffries, R. K. Hanson, Appl. Opt. 52 (33) (2013) 7950-62. 25. J. Jones, Fuel 88 (1) (2009) 218-219. 


\section{Figure and table captions}

Table 1. Location of the sensors during the 2-day campaign

Figure 1. (a) Photograph of the biomass gasifier at SP ETC Piteå, Sweden, (b) schematic of the gasifier including the optical access port configuration and the experimental TDLAS sensor setup, DAQ-data acquisition system, (c) top-view of Port 2.

Figure 2. Results of the TDLAS measurements at Ports 1 and 2 of the EFG reactor firing Peat (Day 1, left column) and Wood (Day 2, right column) at lambdas of 1.2, 0.7, 0.6, 0.5, 0.4 and 0.35. (a and b) lambda, density-weighted path-averaged gas temperature (Sensor 2, S2) and gas stream TC reading, (c and d) CO, $\mathrm{H}_{2} \mathrm{O}$ (Sensor 1, S1), CO (GC-TCD) and $\mathrm{H}_{2} \mathrm{O}$ (Sensor 2), (e and f) transmission at $1389 \mathrm{~nm}, \mathrm{~K}(\mathrm{~g})$ concentration (Sensor 2) and equilibrium values. At all times during the campaign, Sensors 1 and 2 were installed at different ports. Black lines constitute a Savitzky-Golay smooth of the real-time data (red, circular markers). Representative error bars assuming a $\pm 100 \mathrm{~K}$ uncertainty in temperature were added to the calculated $\mathrm{K}(\mathrm{g})$ equilibrium values.

Figure 3. Soot volume fractions and carbon conversion as a function of stoichiometry for Peat (a) and Wood (b) at both ports, determined with the different sensors. Results from Sensors 1 and 2 are from different times during the campaign.

Figure 4. Several seconds of real-time data from inside the EFG reactor core for Wood at Port 2. (a) CO, soot and background emissions for lambda 0.6 with Sensor 1, (b) gas temperature, $\mathrm{H}_{2} \mathrm{O}, \mathrm{K}(\mathrm{g})$ and soot for lambda 0.7 with Sensor 2. 


\section{Supplemental material}

Table S1. Physical and chemical analysis of the fuels

Table S2. Syngas production at different equivalence ratios determined by Helium tracing 


\section{Supplemental material}

Reference: Alexey Sepman, Yngve Ögren, Zhechao Qu, Henrik Wiinikka and Florian M. Schmidt, Real-time in situ multi-parameter TDLAS sensing in the reactor core of an entrained-flow biomass gasifier, Proc. Combust. Inst. 36, 2016

Table S1. Physical and chemical analysis of the fuels

\begin{tabular}{|c|c|c|}
\hline Fuel parameter & Peat & Wood \\
\hline \multicolumn{3}{|l|}{ Powder size distribution (wt \%) } \\
\hline$<40 \mu \mathrm{m}$ & 17.3 & 1.05 \\
\hline$<75 \mu \mathrm{m}$ & 69.3 & 11.7 \\
\hline$<125 \mu \mathrm{m}$ & 84.3 & 35.5 \\
\hline$<250 \mu \mathrm{m}$ & 92.0 & 52.8 \\
\hline$<500 \mu \mathrm{m}$ & 98.0 & 82.2 \\
\hline$<1000 \mu \mathrm{m}$ & 99.8 & 100 \\
\hline \multicolumn{3}{|c|}{ Proximate analysis (wt \% as received) } \\
\hline Moisture & 9.69 & 4.2 \\
\hline Volatiles & 58.4 & 80.3 \\
\hline Fixed carbon (by difference) & 26.2 & 15.2 \\
\hline Ash & 5.69 & 0.32 \\
\hline \multicolumn{3}{|l|}{ Ultimate analysis (wt\% dry) } \\
\hline $\mathrm{C}$ & 53.2 & 51.6 \\
\hline $\mathrm{H}$ & 5.4 & 6.2 \\
\hline $\mathrm{N}$ & 2.59 & $<0.1$ \\
\hline $\mathrm{Cl}$ & 0.018 & $<0.02$ \\
\hline S & 0.21 & 0.023 \\
\hline $\mathrm{O}$ & 32.3 & 41.8 \\
\hline \multicolumn{3}{|c|}{ Major ash components (mg/kg dry) } \\
\hline $\mathrm{K}$ & 640 & 357 \\
\hline $\mathrm{Fe}$ & 11000 & 28 \\
\hline $\mathrm{Ca}$ & 5300 & 736 \\
\hline $\mathrm{Al}$ & 3500 & 26 \\
\hline $\mathrm{Mg}$ & 850 & 187 \\
\hline $\mathrm{Na}$ & $<120$ & 15 \\
\hline $\mathrm{Si}$ & 12000 & 79 \\
\hline \multicolumn{3}{|c|}{ Calorimetric analysis (MJ/kg dry) } \\
\hline Lower heating value & 20.1 & 19.14 \\
\hline
\end{tabular}


Table S2. Syngas production at different equivalence ratios determined by Helium tracing

\begin{tabular}{lll}
\hline Air equivalence ratio & \multicolumn{2}{l}{ Flowrate $\left[\mathrm{Nm}^{3} / \mathrm{min}\right]$} \\
\cline { 2 - 3 } & Peat & Wood \\
\hline 0.7 & 1.26 & 1.40 \\
0.6 & 1.18 & 1.13 \\
0.5 & 1.07 & 1.05 \\
0.4 & 0.95 & 0.90 \\
0.35 & 0.89 & 0.86 \\
\hline
\end{tabular}

